\title{
Guerras europeas, conflictos civiles, proyectos nacionales. Una interpretación de las restauraciones napolitanas (1799-1866)
}

\author{
European Wars, Civil Conflicts, and National Projects. \\ The Neapolitan Restorations (1799-1866) Revisited
}

\author{
Carmine Pinto \\ Universitá degli Studi di Salerno
}

Recibido: 22-VII-2014

Aceptado: 1-X-2014

\section{Resumen}

La elección de examinar la contrarrevolución a través de sus mayores éxitos, las cuatro restauraciones victoriosas, y su derrota, la restauración fallida, puede enriquecer las perspectivas tradicionales sobre la resistencia y la crisis del Reino de las dos Sicilias. Los conflictos europeos, las guerras civiles, las construcciones estatales y la creación de identidades nacionales modernas son fenómenos que se entrecruzan con la complicada historia del reino napolitano. A través de la perspectiva de las restauraciones, bien dinásticas (1799 y 1815), o bien absolutistas (1821 y 1849), podemos insertar en un esquema interpretativo general la dialéctica entre conflicto interno y crisis internacionales, la interrelación con la formación de las ideas y adscripciones nacionalistas y la comparación con la contrarrevolución en el mundo borbónico. El paradigma del conflicto nos permite también el contraste con el más amplio mundo borbónico, francés y, sobre todo, iberoamericano. De este modo podemos reflexionar tanto sobre el éxito del legitimismo napolitano como sobre los términos de su derrota en 1860 y sobre las razones de su reciente fortuna en el imaginario colectivo italiano.

Palabras clave: Restauración, Reino de Nápoles, Bourbon, guerra civil, contra revolución.

\begin{abstract}
Examining counter-revolution through its greater achievements, that is, the four winning restorations, and also their disastrous fall, that is, the defeated restoration, may contribute to enrich traditional perspectives on the Kingdom of the Two Sicilies' resis-
\end{abstract}


tance and the crisis. European conflicts, civil wars, state constructions and modern national identity shaping are phenomena which intertwine the complicated history of the Neapolitan Kingdom. It is from the perspective of the dynastic (1799 and 1815) and absolutist restorations (1821), that we may insert in a general interpretative scheme the controversy between internal conflict and international crisis, their relationship with the shaping of ideas and nationalist affiliation and, finally, their comparison with the counter-revolution in the Bourbon world. The paradigm represented by this conflict allows for a contrast with the wider French and Spanish-American Bourbon world. We may thus consider both the success of Neapolitan legitimism and its collapse in 1860, as well as the reasons for its recent recovery in the Italian collective awareness.

Keywords: Restoration, Kingdom of Naples, Bourbons, civil war, counter-revolution.

\section{Cuestiones historiográficas y discurso público}

"Generales, oficiales y soldados de Gaeta. La suerte de la guerra nos separa... La traición interna, el asalto de revolucionarios extranjeros, la agresión de un Estado que decíase amigo, nada os ha domado ni cansado. Entre sufrimientos de toda clase, pasando por campos de batalla, afrontando las traiciones más terribles del hierro y del plomo, habéis venido a Capua y a Gaeta, marcando de heroísmo las ribas del Volturno y las orillas del Garigliano, desafiando durante tres meses en estas murallas los esfuerzos de un enemigo dueño de toda la potencia de Italia. Por vosotros está a salvo el honor del ejército de las Dos Sicilias; por vosotros vuestro soberano puede tener la cabeza alta, y en la tierra del exilio donde esperará la justicia de Dios, el recuerdo de vuestra heroica lealtad le será dulcísimo consuelo en las desventuras... no os digo adiós sino hasta luego. Conservadme mientras tanto vuestra lealtad, como os conservará su gratitud y su afecto vuestro rey" ${ }^{1}$.

El 14 de febrero de 1861, Francisco II dejó la fortaleza de Gaeta. Su rendición, después de meses de asedio, fue anunciada con esta proclama, dedicada a los soldados protagonistas de la última defensa del Reino de las Dos Sicilias. No era solo una despedida. El rey de Nápoles declaró su voluntad de volver para restaurar la dinastía legítima. Fue tomado en serio. El mito de la reconquista del reino y el recuerdo de las precedentes restauraciones victoriosas animaron una resistencia legitimista que duró casi un decenio. Todavía en los años setenta del siglo XIX bandas lideradas por ex militares borbones se encontraban en las montañas de los Apeninos. El último fusilamiento de un "brigante" fue ordenado en Potenza en 1875. Diez años después fue capturado un guerrillero fugitivo desde 1861, Cosimo Giordano.

1. Proclama reale ai Popoli delle Due Sicilie, Gaeta 14 febbraio 1861, firmato Francesco, manifesto a stampa. 
El mito de una renovada restauración borbónica tenía bases sólidas. El reino de las Dos Sicilias había conocido, antes de la crisis de 1860, cuatro regímenes revolucionarios (republicano en 1799, imperial en 1806, liberal constitucional en 1820 y en 1848), pero también cuatro restauraciones absolutistas (1799, $1815,1821,1849)$. Se trataba de un caso único, respecto a otros movimientos contrarrevolucionarios. Las esperanzas de Francisco II eran comprensibles. El legitimismo napolitano que había mostrado una extraordinaria capacidad de resistencia a las fuerzas del imperio napoleónico y de la revolución liberal, podía oponerse también al nacionalismo italiano. Una tesis aún fuerte en la memoria del Mezzogiorno de la que son testimonios recientes una gran cantidad de libros de éxito, portales electrónicos, asociaciones o eventos².

En general, las celebraciones del 150 aniversario de la Unificación (2011) han estimulado una discusión amplia sobre el Risorgimento italiano. Algunos estudiosos han ponderado las instituciones de los viejos estados y ha recibido mucha atención la historiografía sobre la narración romántica nacionalista y su hegemonía en la península ${ }^{3}$. La crisis final del Reino de las Dos Sicilias ha sido el argumento más controvertido y viciado por la retórica del conflicto político que se debate entre una visión tradicional, que considera inevitable la Unificación, y una lectura que describe una violenta destrucción de los antiguos estados italianos. La actualidad historiográfica y cultural del tema ha planteado la necesidad de renovar métodos y fuentes, sin buscar una revancha sobre las tendencias historiográficas de los decenios pasados o sobre las retóricas coyunturales. De este modo, aun partiendo de los resultados de las interpretaciones consolidadas en el siglo XX, centradas en las características

2. Alianello, Carlo, La conquista del sud, Milano, Rusconi, 1972; Topa, Michele, I Briganti di Sua Maestà, Napoli, Fausto Fiorentino Editore, 1993; Viglione, Massimo, La Vandea italiana. Le insorgenze controrivoluzionarie dalle origini al 1814, Milano, Effedieffe, 1995; SelvagGi, Roberto Maria, Ferdinando II di Borbone - Storia di un sovrano napoletano. Trent'anni di regno tra progresso e reazione, Roma, Newton, 1996; Pellicciari, Angela, Risorgimento da riscrivere, Milano, Ares, 1998; DE BIASE, Erminio, L'Inghilterra contro il regno delle Due Sicilie, Napoli, Controcorrente, 2002; Del BocA, Lorenzo, Indietro Savoia, Storia controcorrente del Risorgimento, Casale Monferrato, Piemme, 2003; Izzo, Fausto, I lager dei Savoia, Napoli, Controcorrente, 1999; CAmpolieti, Giuseppe, Re Franceschiello, L'ultimo sovrano delle Due Sicilie, Milano, Mondadori, 2005; D’AmOre, Fulvio, Uccidete José Borges, Napoli, Controcorrente, 2010; Di Fione, Gigi, Controstoria dell'unità d'Italia - Fatti e misfatti del Risorgimento, Milano, Rizzoli, 2010; SAlera, Luciano, La storia manipolata, Napoli, Controcorrente, 2009.

3. BAnTI, Alberto Mario, La nazione del Risorgimento. Parentela, santità e onore all'origine dell'Italia unita, Torino, Einaudi, 2006; BANTI, Alberto Mario y GINSBORG, Paul (coords.), Il Risorgimento, Torino, Einaudi, 2007; MerigGI, Marco, Gli stati italiani prima dell'Unità. Una storia istituzionale, Bologna, Il Mulino, 2002; Spagnoletti, Angeloantonio, Storia del Regno delle Due Sicilie, Bologna, Il Mulino, 1997. 
del movimiento revolucionario meridional y en las fracturas, de tipo social o territorial, internas del viejo estado napolitano, se ha ampliado el horizonte a nuevas líneas de investigación ${ }^{4}$. El estudio de la guerra y del conflicto civil se ha convertido en un terreno de innovación historiográfica, dado que el Reino de las Dos Sicilias fue el principal lugar de experimentación del enfrentamiento fratricida entre italianos en el siglo XIX ${ }^{5}$.

Este paradigma ha hecho posible una mayor atención, además de al nacionalismo italiano, al movimiento legitimista napolitano, todavía poco conocido y estudiado. En este sentido, la elección de examinar la contrarrevolución a través de sus mayores éxitos, las cuatro restauraciones victoriosas, y su desastrosa derrota, la restauración fallida puede enriquecer otras perspectivas consolidadas $^{6}$. El paradigma del conflicto sirve también para romper con la dimensión regional situando el fenómeno en el contexto mucho más amplio del mundo borbónico, francés y, sobre todo, iberoamericano ${ }^{7}$. Guerras civiles, formación o transformación de nuevos estados, creación de identidades nacionales modernas son por tanto fenómenos que se entrecruzan con la complicada historia del reino napolitano. A través de la perspectiva de las restauraciones, ya sea dinásticas (1799 y 1815) o absolutistas (1821 y 1849), podemos insertar en un esquema interpretativo general la dialéctica entre conflicto interno y

4. Della Peruta, Franco, I Democratici e la rivoluzione italiana, dibattiti ideali e contrasti politici all' indomani del 1848, Milano, Feltrinelli, 1958; RomeO, Rosario, Risorgimento e capitalismo, Bari, Laterza, 1959; BERTI, Giuseppe, I democratici e l'iniziativa meridionale nel Risorgimento, Milano, Feltrinelli, 1961; LePRE, Aurelio, Storia del Mezzogiorno d'Italia, Napoli, Liguori, 1986; Petrusewicz, Marta, Come il meridione divenne una questione. Rappresentazioni del sud prima e dopo il Quarantotto, Rubbettino, Soveria Mannelli, 1998; MACRI, Paolo, Ottocento. Famiglia, élites e patrimoni a Napoli, Bologna, Il Mulino, 2002; Galasso, Giuseppe, Storia del Regno di Napoli, V, Il Mezzogiorno borbonico e risorgimentale (1815-1860), Torino, UTET, 2006; CROCE, Benedetto, Storia d'Europa nel secolo decimonono, Milano, Adelphi, 2007 (ed. or. 1928); Gramsci, Antonio, Il Risorgimento, Roma, La riflessione, 2008 (ed. or. 1949); De LoREnzo, Renata, Borbonia felix. Il Regno Delle Due Sicilie alla vigilia del crollo, Roma, Salerno, 2013.

5. Lupo, Salvatore, L’unificazione italiana. Mezzogiorno, rivoluzione, guerra civile, Roma, Donzelli, 2011; PINTO, Carmine, "1857. Conflitto civile e guerra nazionale nel Mezzogiorno", Meridiana, $\mathrm{n}^{\circ} 69$ (2011), pp. 171-200.

6. Sutherland, Donald, France 1789-1815: Revolution and Counterrevolution, New York, Oxford University Press, 1986; ScHnuR, Roman, Rivoluzione e guerra civile, Milano, Giuffré, 1986; Viola, Paolo, Il crollo dell'antico regime. Politica e antipolitica nella Francia della rivoluzione, Roma, Donzelli, 1993; Tilly, Charles, Le rivoluzioni europee 1492-1992, Roma-Bari, Laterza, 1993; RANZATO, Gabriele (coord.), Guerre fratricide. Le guerre civili in età contemporanea, Torino, Bollati Boringhieri, 1994; Di RIENzo, Eugenio (coord.), Nazione e controrivoluzione nell'Europa contemporanea 1799-1848, Milano, Guerini e associati, 2004.

7. Pinto, Carmine, "Crisi globale e conflitti civili. Nuove ricerche e prospettive storiografiche". Meridiana, no 78 (2013), pp. 9-30. 
crisis internacionales, entramado con la formación de ideas y afiliaciones nacionalistas, la comparación con la contrarrevolución en el mundo borbónico. De este modo podemos reflexionar tanto sobre el éxito del legitimismo napolitano como sobre los términos de su caída en 1860 y las razones de su reciente fortuna en el imaginario colectivo italiano.

\section{Las restauraciones dinásticas. Crisis internacionales y conflictos civiles}

Las primeras restauraciones fueron un producto explícito de la gran guerra europea. En Nápoles, la oleada revolucionaria de los años noventa se insertó en las tensiones que desde hacía años movilizaban a los defensores de los antiguos privilegios y a los centralizadores ilustrados (en Sicilia, por ejemplo, el virrey Caracciolo estuvo en el centro del enfrentamiento entre la tendencia absolutista napolitana y la constitucionalista liberalizante siciliana ${ }^{8}$ ). En un breve período de tiempo esta confrontación fue superada y desapareció sustituida por proyectos políticos y contrastes ideológicos muy diferentes ${ }^{9}$. En el reino meridional emergieron las primeras redes francófilas (represiones y condenas de 1794-7), mientras la relación del estado borbónico con la guerra europea se recrudeció con la operación relámpago del almirante francés Latouche Tréville en Nápoles y la alianza naval con la Inglaterra de Fernando IV, seguida de la expedición napolitana a Toulon ${ }^{10}$.

La crisis, iniciada con la campaña italiana de Napoleón, estalló con la caída del estado pontificio, la intervención militar en Roma y la inmediata reacción francesa. La invasión estuvo acompañada del pronunciamiento de los revolucionarios napolitanos, provocó la ocupación del reino continental, la fuga a Sicilia del rey y la proclamación de la República Partenopea. El Mezzogiorno se convirtió en un sangriento teatro donde se mezclaron la guerra entre los franceses y la coalición enemiga (con la prepotente presencia de Nelson), el conflicto civil entre republicanos y sanfedistas y las tensiones sociales en las provincias. La república, aunque efímera y lacerada, movilizó fuerzas importantes. La guerra, que implicó con intensidad a cada ciudad y a cada pueblo, cambió para siempre la historia del reino y mostró por primera vez, como escribió Cuoco, la

8. SCHIPA, Michelangelo, Il regno di Napoli al tempo di Carlo di Borbone, Milano-Roma-Napoli, Albrighi e Segati 1923; Venturi, Franco, Settecento riformatore. Da Muratori a Beccaria, Torino, Einaudi, 1969; RAO, Anna Maria, Il regno di Napoli nel Settecento, Napoli, Guida, 1983.

9. De RugGIERo, Guido, Il pensiero politico meridionale nei secoli XVIII e XIX; Bari, Laterza, 1954.

10. BARRA, Francesco, Il Mezzogiorno nelle relazioni internazionali, en Storia del Mezzogiorno, Napoli, Edizioni del Sole, 1991. 
existencia de naciones opuestas ${ }^{11}$. Solo en los seis meses de 1799 en los cuales se enfrentaron la República y la Santa Fede se contaron decenas de miles de muertos ${ }^{12}$.

El derrumbamiento de la república, provocado por la ofensiva aliada y el ejército de la Santa Fede de Ruffo, dio paso a la Primera restauración borbónica en Nápoles ${ }^{13}$. El primer acto fue la masacre de los máximos responsables republicanos y el masivo encarcelamiento de sus partidarios. El régimen buscó después una tranquilidad internacional con el apoyo de los ingleses y la paz con Francia para estabilizar el reino a través de un vínculo externo. La estrategia de confiar también el equilibrio, o la protección, a las grandes potencias, ha explicado Galasso, será durante decenios el pilar de la política borbónica (junto a la alianza con la Iglesia y algunos sectores populares) ${ }^{14}$. Se decidieron algunas moderadas reformas antifeudales para buscar el consenso de la opinión pública menos conservadora del reino, pero no fueron capaces de resolver la inestabilidad financiera y la petición de cambios políticos (frecuentemente tenían una intención punitiva, como la abolición de los privilegios materiales de la nobleza). El indulto (1800) evitó que se continuara con la masacre de los republicanos (que eligieron la vía del exilio en masa). Finalmente, los protagonistas de la contrarrevolución fueron masivamente incorporados a la aristocracia y a las estructuras del estado para crear una nueva base legitimista. La Primera restauración consiguió clausurar la fase de emergencia, pero no pacificó el reino, ni obtuvo un auténtico reconocimiento internacional ${ }^{15}$. El elemento más evidente fue la ruptura con una parte importante de los notables y de la intelectualidad, del ejército y de los funcionarios, que se alinearon con la república (y luego, a escala mucho mayor, con el imperio), pensando en la modernización del reino y en su propia inserción en una élite paneuropea que sustituyera a la integrada en el viejo mundo borbónico. Al mismo tiempo, alrededor de la dinastía se congregaron partes importantes de la aristocracia, de

11. Cuoco, Vincenzo, Saggio storico sulla rivoluzione di Napoli, Manduria, Lacaita, 1998

12. Ilari, Virginio, Crociani Piero y Paoletti Ciro, Storia militare dell'Italia giacobina (17961802), Roma, USSME, 2001.

13. Croce, Benedetto, La rivoluzione napoletana del 1799. Biografie, racconti, ricerche, Bari, Laterza, 1912; Petraccone, Claudio, Napoli nel 1799. Rivoluzione e proprietà, Napoli, Morano, 1989; RAO, Anna Maria (coord.), Napoli 1799 fra storia e storiografia, Napoli, Vivarium, 2002; Di Francesco, Antonino, 1799. Una storia d'Italia, Milano, Guerini e Associati, 2004.

14. Galasso, Giuseppe, Storia del Regno di Napoli, V, Il Mezzogiorno borbonico e napoleonico (1734-1815), Torino, UTET, 2006.

15. Piero, Pieri, "Il regno di Napoli dal luglio 1799 al marzo 1806", ASPN, no LII (1926), pp. 136-286; Blanch, Luigi, Scritti storici, Bari, Laterza, 1945; RaO, Anna Maria, Esuli: l'emigrazione politica italiana in Francia: 1792-1802, Napoli, Guida, 1992. 
los notables locales, del ejército, con una mayor prevalencia de la iglesia y de las clases populares, que hicieron de la contrarrevolución un proyecto alternativo, con una ideología propia y un diseño político, frecuentemente heredero de la misma tradición ilustrada, fundado sobre el objetivo de una restauración que combinó los valores de la lealtad monárquica y aquellos de la tradición napolitana ${ }^{16}$. Si en 1799 la gran masacre entre los napolitanos encontró un analista de éxito en el volumen del exilado republicano Cuoco, al otro lado de la barricada estuvo el padre sanfedista Cimbalo, autor de uno de los superventas del momento, con el volumen que describía la emocionante marcha del cardenal Ruffo. Se definió, en conclusión, un pensamiento contrarrevolucionario, dotado también de una dialéctica interna muy semejante a aquella que se había desarrollado en el campo contrario, pero basada en un bloque político y social que reunía instituciones y grupos sociales, reivindicando en la nueva relación entre Iglesia y trono un formidable cemento ideológico ${ }^{17}$.

La Primera restauración no consiguió neutralizar el conflicto interno, convertido en el elemento central de la lucha política y del desarrollo del estado. Cuando se reanudó la guerra europea la ruptura volvió a plantearse estrechamente vinculada a la crisis internacional. La ruptura de la paz de Amiens, la torpe política de los borbones (una confusa ambigüedad entra Napoleón e Inglaterra), llevaron a una segunda invasión francesa (1806). El rey y la corte se trasladaron a Palermo, bajo la protección inglesa. Inició el Decenio, con la presencia de dos reyes (José Bonaparte y luego Joaquín Murat), marcado por la inserción del reino en la política europea de Napoleón y por la ruptura definitiva con las formas y las prácticas de la ilustración dieciochesca. Las más importantes reformas administrativas de la historia napolitana (institucionalización de las comunidades locales y provinciales, del consejo de estado y de las nuevas magistraturas, abolición del feudalismo y promulgación de los códigos), registraron la adhesión masiva de sectores importantes del Mezzogiorno al nuevo régimen y a la política napoleónica a través de las instituciones políticas y del ejército ${ }^{18}$. Esta elección de campo no impidió la continuación de un sangriento conflicto civil que una vez más se mezcló con la guerra en curso

16. LEONI, Francesco, Storia della controrivoluzione in Italia (1789-1859), Napoli, Guida, 1975; Mascilli Migliorini, Luigi, Il mito dell'eroe, Napoli, Guida, 2003; De Lorenzo, Renata, Murat, Roma, Salerno, 2011.

17. LEONI, Francesco, Il pensiero controrivoluzionario in Italia, Napoli, Istituto editoriale del Mediterraneo, 1972.

18. CORTESE, Nino, L'esercito napoletano e le guerre napoleoniche (Spagna, Alto Adige, Russia, Germania), Napoli Ricciardi, 1928; SCOTTI Douglas, Vittorio (coord.), Gli italiani in Spagna nella guerra napoleonica (1807-1813). I fatti, i testimoni, l'eredità, Alessandria, Edizioni dell'Orso, 2006. 
en el Mediterráneo y en Europa. La política borbónica tuvo que renovarse para enfrentarse al éxito de los napoleónicos, aceptando la constitución siciliana (1812), participando en la política inglesa e intentando ofrecer nuevas perspectivas a sus partidarios. El reino conoció todo el repertorio posible de la violencia política: presencia en los ejércitos europeos, actividades secretas, organizaciones paramilitares, guerrilla rural, movilizaciones de aparatos logísticos, conflictos locales ${ }^{19}$. Los contrarrevolucionarios tenían que enfrentarse con una poderosa crisis, pero en el fuego del conflicto reforzaron la identificación con un patriotismo leal y católico que contraponer al proyecto paneuropeo imperial napoleónico.

Las consecuencias de la guerra determinaron la Segunda restauración borbónica en 1815. La derrota de Murat (y su fusilamiento) puso fin para siempre a la experiencia francesa. El nuevo estado, el Reino de las Dos Sicilias, en el interior del ajedrez geopolítico definido en Viena, se presentó como la mayor potencia italiana: exponentes de su clase dirigente (el príncipe de Canosa) pensaban incluso en una expansión por la península ${ }^{20}$. La tradición nacional no había estado ni siquiera cuestionada en el Decenio francés (Murat había impuesto en 1811 la nacionalización napolitana a los funcionarios extranjeros) y por tanto la Restauración apuntó hacia una política de equilibrios y pacificación, bajo la égida del comprensivo y atento imperio Habsburgo, con la construcción de un nuevo edificio estatal: el Reino de las Dos Sicilias. Los resultados del conflicto civil condicionaron la Segunda restauración, pero en la dirección opuesta a 1799. El gobierno de Fernando I, con la política de la amalgama, representada por Luis de Médici y sostenida por Metternich, intentó cerrar la fractura interna, a través de la conservación de las instituciones de los napoleónicos y la integración de funcionarios, notables y militares muratianos en el aparato del estado (convención de Casalanza, 1815). Al mismo tiempo, el compromiso con la Iglesia (concordato de Terracina, 1818), cerró las fracturas dieciochescas entre los borbones y el mundo eclesiástico ${ }^{21}$.

19. VALENTE, Angela, Gioacchino Murat e l'Italia meridionale, Torino, Einaudi, 1927; SAVARESE, Giacomo, Tra rivoluzioni e reazioni. ricordi di Giuseppe Zurlo, Torino, Einaudi, 1941; Della Peruta, Franco, Esercito e società nell'Italia napoleonica, Milano, Angeli, 1988; Woolf, Stuart, Il Risorgimento italiano, Torino, Einaudi, 1981; LePrE, Aurelio (coord), Studi sul Regno di Napoli nel Decennio francese (1806-1815), Napoli, Liguori, 1985; BARRA, Francesco, Il decennio francese nel Regno di Napoli (1806-1815). Studi e ricerche, Salerno, Plectica, 2008.

20. MATURI, Walter, "Il Congresso di Vienna e la Restaurazione dei Borboni a Napoli", Rivista Storica Italiana, $\mathrm{n}^{\circ} 3$ (1938), pp. 32-72.

21. Maturi, Walter, Il Concordato del 1818 tra la Santa Sede e le Due Sicilie, Firenze, Le Monnier, 1929; Borzomati, Pietro, Chiesa e società meridionale. Dalla Restaurazione al $2^{\circ}$ dopoguerra, Roma, Studium, 1982. 
La Segunda restauración llevó hasta las últimas consecuencias las líneas de la monarquía administrativa, combinando las nuevas formas y estructuras del poder con el objetivo de dilatar las dimensiones del consenso y de la integración en el régimen ${ }^{22}$. En el plano ideológico, considerando el decenio como mera ocupación, sus cambios fueron asimilados insertándolos en las tradiciones jurídicas meridionales. La dinastía había asegurado el retorno a la independencia del antiguo estado napolitano, juntando el espíritu reformador borbónico dieciochesco y la resistencia antifrancesa (presentada como una guerra de liberación liderada por el pueblo) ${ }^{23}$. Además, para consolidar el poder de la corona, fue perfeccionada y extendida a Sicilia la monarquía administrativa, ahora duramente hostilizada por el autonomismo insular ${ }^{24}$. La política de Médici se basaba en la idea de que el equilibrio internacional y la pacificación interna podían estabilizar el reino y determinar una modernización definitiva del nuevo organismo estatal, manteniendo un compromiso entre lo viejo y lo nuevo, entre el absolutismo dieciochesco y el reformismo francés ${ }^{25}$. El régimen subestimó el alcance de la ruptura político-ideológica, que también había obligado a Fernando IV a conceder la constitución en Sicilia (1812), a José Bonaparte a ponerla en marcha en Bayona (1808, inmediatamente abandonada por su sucesor) y a Murat a hacer lo mismo en los últimos días de su reinado (1815). Un fenómeno evidente en la consolidación de una masiva oposición política clandestina, multiplicada bien por los efectos de la retirada de la constitución (en Sicilia) o bien por las consecuencias políticas y psicológicas de la posguerra en el Mezzogiorno ${ }^{26}$.

Esta profunda politización condicionó las dos restauraciones, en el centro de las cuales estuvo siempre la cuestión de la legitimidad y del restablecimiento de la dinastía, pero en el interior de retóricas y proyectos políticos modernos. La contrarrevolución napolitana contrapuso un modelo de legitimidad basado en la transmisión dinástica y el patriotismo leal a uno de tipo primero republicano-revolucionario, luego imperial paneuropeo. El conflicto por la titularidad

22. Ghisalberti, Carlo C., Contributo alla storia delle amministrazioni preunitarie, Milano, Giuffré, 1963; Galasso, Giuseppe, Potere e istituzioni in Italia. Dalla Caduta dell'impero romano ad oggi, Torino, Einaudi, 1974.

23. De Angelis, Francesco, Storia del Regno di Napoli sotto la dinastia borbonica, Napoli, Morosino, 1817.

24. Tomeucci, Luigi, Genesi del conflitto tra la Sicilia e I Borboni (1734-1817), Bologna, Zanichelli, 1964; Romeo, Rosario, Il Risorgimento in Sicilia, Roma-Bari, Laterza, 1970.

25. Scirocco, Alfonso, Dalla seconda restaurazione alla fine del regno, en Storia del Mezzogiorno...

26. MATURI, Walter, La politica estera napoletana dal 1815 al 1820, Rivista Storica Italiana, $\mathrm{n}^{\circ} 4$ (1939), pp. 226-272; RoMEo, Rosario, Mezzogiorno e Sicilia nel Risorgimento, Napoli, ESI, 1963. 
del poder no cuestionó la identidad nacional napolitana, pero provocó una escisión entre las diversas hipótesis de soberanía dinástica y de colocación ideológica. Las dos restauraciones respondieron a estos desafíos con dos políticas diferentes, si no opuestas, en 1799 y en 1815 , pero no consiguieron neutralizar las desavenencias políticas, ideológicas, territoriales, justamente por la interrelación entre el conflicto interno y la guerra europea.

\section{Las restauraciones absolutistas. Conflictos civiles y proyectos nacionales}

La formación de tradiciones y culturas políticas contrapuestas, difusas y radicadas en todos los rincones del estado, ofreció un terreno fértil a aquellos que aplaudieron la revolución en España de $1820^{27}$. Solo la profundidad de la desavenencia político-ideológica puede explicar los términos del motín napolitano, después de una Restauración moderada que durante cinco años había tutelado a todos los protagonistas de las etapas pasadas. El embajador austriaco escribió que podía esperarse la revolución en cualquier lugar, también en la luna, pero no en Nápoles ${ }^{28}$. Esta vez fueron los liberales napolitanos y los autonomistas sicilianos, no un ejército extranjero, quienes determinaron la crisis del reino. El movimiento carbonario había aglutinado a todos los descontentos y opositores, haciendo emerger la hostilidad de amplios estratos de la población contra la política de la Restauración. Sicilia, una vez retirada la constitución, se había convertido en un elemento de inestabilidad continua. $\mathrm{Al}$ inicio de la revolución, los carbonarios obtuvieron el apoyo de los militares muratianos. El rey concedió inmediatamente la constitución y soportó la formación de un gobierno liberalizante, controlado por exponentes moderados. El movimiento revolucionario estaba, no obstante, fragmentado entre las facciones carbonarias, además de entre constitucionales y exmuratianos ${ }^{29}$. Además, tuvo que sofocar la revuelta autonomista de Sicilia, fragmentando ulteriormente el frente revolucionario, obligado a librar una lucha sin cuartel justamente con sus aliados potenciales ${ }^{30}$. Pocos meses después Fernando I llegó al Congreso de la Santa Alianza en Ljiubliana (que decidió la intervención contra las revoluciones mediterráneas), y luego volvió a Nápoles junto al ejército habsburgo. El ejército napolitano fue derrotado rápidamente, y el absolutismo restaurado por una fuerza de ocupación austriaca.

27. SPINI, Giorgio, Mito e realtà della Spagna nelle rivoluzioni italiane del 1820-21, Roma, Perrella, 1950.

28. Schipa, Michelangelo, Il regno di Napoli sotto i Borboni, Napoli, Pierro, 1900.

29. Colletta, Pietro, Storia del reame di Napoli. Dal 1734 al 1825, Torino, Pomba, 1853; LEPRE, Aurelio, La rivoluzione napoletana del 1820-21, Roma, Editori Riuniti, 1967.

30. CORTESE, Nino, La prima rivoluzione separatista siciliana, 1820-1821, Napoli, Libreria Scientifica, 1951. 
La Tercera restauración tuvo caracteres genuinamente político-institucionales, no había la necesidad de restablecer la soberanía de la dinastía. El régimen borbónico intentó crear una renovada comunidad política de tipo conservador absolutista, reforzando el poderoso bloque social que había constituido a partir de 1799. La consolidación del estado pasó también por la creación de organismos consultivos (queridos por Metternich) en el Mezzogiorno y en Sicilia, para intentar superar el creciente alejamiento entre Nápoles y la isla. En todo caso, ni siquiera la Tercera restauración consiguió solucionar el desencuentro entre revolución y contrarrevolución, por la presencia ya consolidada de tradiciones políticas liberales y la fractura con buena parte de las élites sicilianas. El conflicto civil, aunque limitado, quedó como el instrumento de la organización de las luchas entre facciones y proyectos políticos generales. Desde aquel momento la Constitución devino un instrumento siempre aborrecido por los borbónicos, salvo pocas excepciones (como Pietro Ulloa): era la premisa natural de la guerra civil o de la crisis del estado. Todavía diez años más tarde del final del estado napolitano, Filippo Pisacane, aristócrata y coronel de caballería (hermano del famoso revolucionario Carlo), en el exilio con la familia real hasta su muerte, sostuvo que fue la elección de la Constitución la que determinó la caída del Reino: la pluma rehúsa detallar la serie de los hechos llevados a cabo, bajo el manto de la más vil hipocresía para que el rey cayera en el lazo de conceder franquía al Pueblo"31. El régimen realizó una dura represión de todos los protagonistas del régimen constitucional (además del motín de julio), pero el liberalismo napolitano y siciliano quedó como una fuerza de oposición consistente, dotado de una resonancia internacional multiplicada por los miles de exiliados ${ }^{32}$.

Además de castigar al enemigo interior, en el decenio sucesivo se sentaron la bases para la renovación borbónica de los años treinta y sobre todo para superar la penosa tutela internacional, confirmada por la ocupación austriaca, que si bien había sido solicitada por el rey, no por eso resultaba menos humillante ${ }^{33}$. Precisamente para quebrar la conexión entre las intervenciones internacionales y los conflictos internos, el nuevo rey, Fernando II, intentó una política de nacionalización del estado, reforzando un ejército fiel al trono, convirtiendo la alianza con la Iglesia en un acuerdo de hierro, intentando una consistente

31. Pisacane, Filippo, Un poco più di vero su fatti d'armi operati da resti dell'Esercito Napolitano nel 1860 e sulle cagioni che li produssero pel Duca di San Giovanni, Napoli,1874.

32. IsABella, Maurizio, Risorgimento in esilio: l'internazionale liberale e l'età delle rivoluzioni, Roma-Bari, Laterza, 2011.

33. Cingari, Gaetano, Mezzogiorno e Risorgimento. La Restaurazione a Napoli dal 1821 al 1830, Bari, Laterza, 1976; DAVIS, John, Naples and Napoleon. Southern Italy and the European Revolutions 1780-1860, Oxford, Oxford University Press, 2009. 
apertura económica y una moderada integración de los exmuratianos y de las élites sicilianas. Su programa nacional aseguró el éxito de la Tercera restauración, pero ni siquiera su acción consiguió integrar viejas y nuevas corrientes de oposición política que, como en los decenios pasados, se insertaron en las fracturas sociales, territoriales y morales del reino. La revolución de 1848 confirmó la conexión entre crisis externas y fracturas internas, con una novedad importante: constitución y absolutismo empezaron a entrelazarse con palabras clave como unificación o independencia, mezclando reivindicaciones autonomistas, constitucionalismo liberal, democracia radical, nacionalismo italiano. La primera insurrección fue en Palermo, en enero de 1848. El rey concedió la Constitución. Durante algunos meses acompañó las peticiones del gobierno moderado, luego, utilizando las divisiones entre los liberales y la derrota de los nacionalistas italianos en el valle padano, empezó a desmoronar el edificio constitucional ${ }^{34}$. En pocos meses demolió la revolución. En 1849 la contrarrevolución napolitana fue la de mayor éxito en Italia. Fernando II fue el principal representante del legitimismo de su generación, capaz de derrotar por sí solo el movimiento liberal napolitano y siciliano. Había superado la insurrección siciliana, reprimido las revueltas de Cilento y Calabria, acabado en pocas horas con las barricadas napolitanas del 15 de mayo, obteniendo declaraciones de lealtad de parte de las élites locales que se colocaban siempre en la frontera entre conservación y cambio.

La Cuarta restauración, como la precedente, no tuvo que restablecer el edificio monárquico o la autonomía del estado. La máquina administrativa y represiva continuó funcionando con eficiencia, sectores importantes del reino conservaron la fidelidad al trono y al estado, fue promovida la política económica del rey y estimulado el orgullo nacional. Sin embargo, precisamente la voluntad de radical autonomía del rey acentuó las fracturas internacionales e internas, rompiendo el esquema tradicional de la política borbónica que confiaba a las grandes potencias las garantías últimas de la existencia del reino. Ingleses y franceses establecieron un progresivo aislamiento (el caso más famoso fue el de las cartas de Lord Gladstone), reforzando una opinión pública internacional que consideraba a las Dos Sicilias como un auténtico anacronismo histórico ${ }^{35}$. Además, la dura represión del movimiento liberal (derrotado también en sus

34. Paladino, Giuseppe, La rivoluzione napoletana del 1848, Milano, Vallardi, 1914; MosCaTI, Ruggero, Ferdinando di Borbone nei rapporti diplomatici austriaci, Napoli, ESI, 1947; idem, I Borboni d'Italia, Roma, Newton Compton, 1973; Brancato, Francesco, La Dittatura garibaldina nel Mezzogiorno e in Sicilia, Trapani, Celebes, 1965.

35. ZAzo, Alfredo, La politica estera del Regno delle Due Sicilie nel 1959-60, Napoli, Miccoli, 1940; Di Rienzo, Eugenio, Il Regno delle Due Sicilie e Le Potenze Europee. 1830-1861, Soveria Mannelli, Rubbettino, 2012. 
modestos intentos de los años cincuenta), no consiguió detener la radicalización en el Mezzogiorno. En fin, la resolución fallida de la cuestión siciliana convenció a las élites insulares de que su causa solo podría solucionarse en el ámbito del proyecto nacional italiano ${ }^{36}$. Todo ello hizo todavía más complicado el intento de restaurar una política absolutista tradicional sobre la base de los principios de 1815 y de 1821 en la Italia donde se extendía el romanticismo nacionalista panitaliano.

En el decenio de la cuarta restauración esta apertura se hizo cada vez más radical. El debate sobre la definición geográfica, burocrática e ideológica del estado, permite identificar los materiales de una renovada confrontación entre proyectos estatales ${ }^{37}$. Una parte importante del Mezzogiorno eligió definitivamente la patria italiana ideada por los liberales, como parte de una frontera cultural más amplia, dotada también en el Reino de las Dos Sicilias de una tradición política característica, que tenía la propia legitimidad en decenios de revoluciones y conspiraciones, se identificaba en la libertad constitucional y compartía un proyecto con las fuerzas ideológicamente hegemónicas en la península (apoyadas por la opinión pública liberal europea). A este proyecto nacional el legitimismo meridional contrapuso una patria napolitana con un pasado dividido, basado en la renovación de la monarquía administrativa, en un paternalismo afectuoso que, junto al rigor de las leyes, debía garantizar el bienestar de los súbditos y la defensa de las antiguas tradiciones, en la independencia y en la fidelidad dinástica. En los años de la tercera y, sobre todo, de la cuarta restauración estos sentimientos adquirieron nuevos significados, llegando a reconstruir la unidad cultural del pueblo napolitano a través de una idea de comunidad nacional dotada de un sentido de pertenencia territorial, política y cultural. La nación era una herencia que se impulsaba avalada por

36. GuARDione, Francesco, Le reazione borbonica in Sicilia e il trionfo della rivoluzione unitaria, Palermo, Sanzo, 1929; Moscati, Ruggeri, Il Mezzogiorno d'Italia nel Risorgimento, Firenze-Messina, D'Anna, 1953; RendA, Francesco, Risorgimento e classi popolari in Sicilia, Milano, Feltrinelli, 1968; Riall, Lucy, La Sicilia e l'unificazione italiana. Politica liberale e potere locale (1815-1866), Torino, Einaudi, 2004.

37. Anderson, Benedict, Imagined Communities: Reflections on the Origin and Spread of Nationalism, London, Verso, 1993; Hutchinson, John y SMith Anthony D. (coords.), Nationalism, Oxford, Oxford University Press, 1994; Breully, John, Nationalism and the State, Manchester, Manchester University Press, 1993; Gellner, Ernst, Nations and Nationalism, Oxford, Blackwell, 1983; Hastings, Anthony, The Construction of Nationhood: Ethnicity, Religion and Nationalism, Cambridge, Cambridge University Press, 1997; Hobsbawm, Eric J., Nations and Nationalism Since 1780: Programme, Myth, Reality, New York, Cambridge University Press, 1990; SMith, Anthony D., The Ethnic Origins of Nations. Oxford, Blackwell, 1998. 
las generaciones precedentes. Rechazada la solución constitucional, el patriotismo era la única respuesta posible al desafío nacionalista italiano ${ }^{38}$. La última restauración absolutista se fundó precisamente en el desencuentro con la élite panitaliana. 1848 había confirmado que la patria se identificaba con quien defendía la autonomía y las tradiciones. Fernando II, recordó Ruggero Moscati, "napolitano, él sentía la 'nación napolitana', no la nación italiana", no había solicitado la intervención de los ejércitos extranjeros para sofocar la revolución, reivindicando una legitimación nacional del viraje autoritario ${ }^{39}$.

La última restauración era la demostración de que en el legitimismo napolitano nación y libertad política no siempre iban juntas. El resultado de las últimas dos restauraciones fue una neta división ideológica y cultural, que contrapuso en el mismo país la patria napolitana y la italiana, mezclando las afiliaciones con los proyectos nacionales, haciendo difícil, si no imposible, conciliar el conflicto interno iniciado sesenta años antes. Rechazadas todas las mediaciones, el problema de la constitución devino una insuperable diferencia entre dos visiones del desarrollo del reino. La consecuencia fue una línea de demarcación entre aquellos que se agruparon alrededor del trono y de las antiguas tradiciones del estado, y aquellos otros que, como escribió Croce, consideraron agotados los deberes de la monarquía borbónica y, por tanto, del propio estado napolitano ${ }^{40}$.

\section{¿Una contrarrevolución victoriosa? Una hipótesis de comparación}

La contrarrevolución napolitana era parte de un relevante fenómeno internacional y, sobre todo, del colapso del sistema borbónico iniciado con la caída de la monarquía francesa. La napolitana tenía además raíces comunes con el mundo iberoamericano en la tradición imperial de los Habsburgo en la cual Galasso, Musi y Villari han colocado la original historia nacional napolitana ${ }^{41}$.

38. CAcCiATORe, Andrea, Esame della Storia del Reame di Napoli di Pietra Colletta dal 1734 al 1825, Napoli, Stabilimento Tipografico, 1850; MuSEI, Mauro, Storia civile e militare del regno delle Due Sicilie sotto il governo di Ferdinando II. Dal 1830 al 1849, Napoli, Poliorama, 1850; Cala' Ulloa, Pietro, De' fatti dell'ultima rivoluzione derivanti da' giudizi politici del reame di Napoli, Napoli, Stamperia Reale, 1854; Rassegna degli errori e delle fallacie pubblicate dal sig. Gladstone in due sue lettere indirizzate al conte di Aberdeen sui processi politici nel reame delle Due Sicilie, Napoli, Fibreo, 1851; Di Gregorio, Eugenio, L'astro nella tenebra. Ovvero l'immortale Ferdinando II re del regno delle Due Sicilie negli orrori dell'ultima rivoltura fino all'attualità, Napoli, Capasso, 1852.

39. Moscati, Ruggero, I Borboni d'Italia..., p. 122.

40. Croce, Benedetto, Storia del Regno di Napoli, Milano, Adelphi, 1992.

41. Musi, Aurelio (coord.), Alle origini di una nazione: antispagnolismo e identità italiana, Milano, Guerini e Associati, 2003; VILlaRI, Rosario, Un sogno di libertà. Napoli nel declino di un impero (1585-1648), Milano, Mondadori, 2012; Galasso, Giuseppe, Alla periferia dell'impero. Il Regno di Napoli nei secoli XVI-XVII, Torino, Utlet, 1994. 
Todas sufrieron una grave crisis de legitimidad, fueron después comprometidas en el enfrentamiento entre liberalismo y absolutismo, y finalmente transformadas en naciones independientes, estados modernos o regiones en el centro de innovadoras experiencias institucionales, frecuentemente mediante una larga repetición de conflictos internos ${ }^{42}$. El legitimismo napolitano se desarrolló en el interior del largo proceso de experimentación de ideas y formas de organización política iniciado con las guerras de la Revolución ${ }^{43}$. El programa al cardenal Ruffo antes de su expedición en el Mezzogiorno estuvo entre los primeros documentos orgánicos en Europa, de mano de un poder institucional, que determinó los objetivos políticos, ideológicos y operativos de la contrarrevolución ${ }^{44}$. No era por tanto una herencia del pasado, sino una consecuencia de la fractura europea entre revolución y contrarrevolución ${ }^{45}$. Cuando se presentó como un movimiento político de masas, en 1799, en el ámbito de la movilización contrarrevolucionaria que convulsionó Francia, Suiza, Holanda y Bélgica, los napolitanos fueron los únicos en tener éxito, creando un potente precedente simbólico y realizando, bajo la égida inglesa, la Primera restauración.

También en el Decenio la contrarrevolución se colocó en un contexto de este tipo, la resistencia de los napoleónicos determinó un estado de guerra permanente y sentó las premisas para legitimar la Segunda restauración, si bien no llegó a movilizar fuerzas comparables a la guerrilla española. La experiencia de la doble invasión (Nápoles 1806-Madrid 1808) admite un cuadro comparativo con el espacio político heredero de las coronas de Carlos III. En España, 1808 avivó un proceso de intensa politización que no se detuvo con la restauración de 1815 y continuó, como ha escrito Rújula, hasta 1840, preparando el terreno a los partidos y movimientos políticos españoles del XIX ${ }^{46}$.

42. Centeno, Miguel Angel, Blood and Deb. War and Nation-State in Latin America, Pennsylvania, The Pennsylvania State University Press, 2002; Regan, Patrick, Sixteen Million One: Understanding Civil War, Boulder, Paradigm, 2009, Pinto, Carmine, La "guerra civil borbónica". Crisis de legitimidad y proyectos nacionales entre Nápoles y el mundo iberoamericano, Santiago de Chile, FEC, 2014.

43. FuRET, François y Richet, Denis, La Révolution française, Paris, Fayard, 1973; idem, Penser la Révolution française, Paris, Gallimard, 1978.

44. Battaglini, Mario, La Repubblica Napoletana, Città di Castello, Bonacci, 1992; Von Helfert, Joseph Alexander, Fabrizio Ruffo. Rivoluzione e controrivoluzione di Napoli dal novembre 1798 all'agosto 1799, Firenze, 1885.

45. Совв, Richard, Reactions to the French Revolution, London, New York, Oxford University Press, 1972; GodECHOT, Jacques, The counter-revolution: doctrine and action, 1789-1804, New York, H. Fertig, 1971; MARTIN Jean-Clement, I bianchi e i blu. Realtà e mito della Vandea nella Francia rivoluzionaria, Milano, SEI, 1989.

46. Hamnett, Brian, La Política Española en Una Época Revolucionaria, 1790-1820, México, Fondo de Cultura Económica, 1985; Cuenca Toribio, José Manuel, La Guerra de la Independencia: un conflicto decisivo, 1808-1814, Madrid, Encuentro, 2006; EsDaile, 
Los defensores del absolutismo en los años veinte, y los carlistas después, no tendrán dificultad en colocar ahí sus propias raíces. En ambos países mediterráneos la restauración legitimista fue posible también gracias a su base interclasista y militante, capaz de un proyecto político adecuado al conflicto interior por el poder y la ideología. Se trata de un modelo comparable con el discutido para la América borbónica donde, superando el concepto de las guerras de la independencia como liberación de naciones preexistentes o conflictos entre grupos populares nativos y colonizadores españoles propietarios de tierras y capital, se ha puesto el conflicto y la crisis de la monarquía en el centro del análisis de las revoluciones de independencia ${ }^{47}$. En todo el espacio de la vieja monarquía, una crisis generalizada puso en discusión la legitimidad del poder, movilizando ambiciones, lealtades y programas, todo lo contrario que convergentes en las élites españolas, napolitanas o americanas. Un particular esquema de fragmentación del concepto de soberanía que asignó al conflicto interno un rol que no tuvo equivalentes análogos en el imperio Habsburgo o en el ruso, por no hablar de Inglaterra o Prusia.

El legitimismo napolitano fue parte de una contrarrevolución producida por el conflicto civil europeo y americano que alcanzó su momento culminante en 1814-1816. Un fenómeno común a casi todo el mundo borbónico, además de a buena parte de Europa, de Santa Fe a Caracas, de Madrid a Palermo (el Río de la Plata fue un caso raro), pero rápidamente puesto en discusión por la resistencia del liberalismo europeo y los independentistas americanos al sistema de Viena. Las restauraciones fueron solo una etapa de un largo proceso de creación de comunidades políticas contrapuestas marcado por la formación de los conceptos de autonomía o por el tema de la invasión extranjera, por el nacimiento de contrapoderes territoriales y organizaciones políticas o militares. Cuando la batalla por la constitución dividió una vez más el mundo borbónico, liberalismo y democracia, legitimismo y neoabsolutismo se encontraron

Charles, The Peninsular War. A New History, New York, Palgrave Macmillan, 2003; Fraser, Ronald, Napoleon's Cursed War: Spanish Popular Resistance in the Peninsular War, 1808-1814, New York, London, Verso, 2008; Rújula, Pedro y CANAL, Jordi (coords.), Guerra de Ideas. Política y Cultura en la España de la Guerra de Independencia, Madrid, Marcial Pons, 2012.

47. Gandía, Enrique de, La independencia americana, Buenos Aires, Los libros del mirasol, 1960; Tutino, John, From Insurrection to Revolution in Mexico: Social Bases of Agrarian Violence, 1750-1940, Princeton, Princeton University Press, 1986; GuERRA, FrançoisXavier, Modernidad e independencias: ensayos sobre las revoluciones hispánicas, Madrid, MAPFRE, 1992; RODRíGUEZ, Jaime, Revolución, independencia y las nuevas naciones de América, Madrid, Fundación Mapfre-Tavera, 2005; Pérez Vejo, Tomás, Elegía criolla. Una reinterpretación de las guerras de independencia hispanoameriacanas, México, Tusquets, 2010. 
en todas partes, si bien a través de iliterarios nacionales diferentes. 1820 ofrece un modelo que evidencia la fragmentación del espacio de la antigua monarquía católica, unificado por la oleada revolucionaria y por la resistencia legitimista, pero quebrado por resultados diferentes ${ }^{48}$. Los regímenes borbónicos no fueron capaces de ofrecer espacios de participación y de intervención a los contestatarios políticos o regionales; en cambio, una vez más ninguno o casi ninguno de los viejos enemigos de Napoleón conoció conflictos internos análogos (Inglaterra, Rusia, Prusia, el Imperio austriaco, los Países Bajos, Dinamarca, Suecia). La victoria de la revolución en América (independencia y formación de las naciones) y la de la contrarrevolución en Europa (intervención internacional en España e Italia) produjo una fractura decisiva: las conexiones globales se redujeron a la diversa influencia de los imperios inglés y francés (que en el Mediterráneo habían ocupado definitivamente el papel de España), a los intercambios de ideas o modelos políticos, a los desplazamientos de exiliados y aventureros en ambos lados del Atlántico.

Los conflictos civiles, producto de la crisis de legitimidad originaria, continuaron, haciendo posible una hipótesis comparativa. En los territorios del otro lado del Atlántico, después de los años veinte, el final del control imperial fue seguido, casi siempre, de guerras internas, raramente resolutivas, que consolidaron, divisiones y comunidades políticas alternativas, alternando treguas, paces confusas o acuerdos. Estos conflictos tenían a veces líneas comunes con la Europa borbónica (la vinculación con la Iglesia católica, la relación entre centro y periferia, entre grupos urbanos y clases rurales) pero raramente pusieron en discusión las nuevas identidades nacionales o hicieron regresar los modelos tradicionales. En el mundo latinoamericano el desencuentro directo entre revolución y contrarrevolución, en los términos tradicionales, había concluido. Como han escrito Pérez-Vejo y López-Álves, el conflicto interno quedó como una regla en gran parte de aquel espacio político, desde México hasta Colombia o Uruguay. Era una confrontación entre liberales y conservadores, federalistas y centralistas, caudillos y centros urbanos, sobre diversos proyectos de nación y estado más que sobre complejos objetivos de poder que continuaron hasta final de siglo ${ }^{49}$.

Revolución y contrarrevolución continuaban batiéndose en España, pero al revés. El liberalismo español impidió a sus enemigos dar un vuelco a los resultados del cambio constitucional, y fue capaz de mantener el poder superando

48. Brown, Matthew y Paquette, Gabriel J. (coords.), Connections after Colonialism: Europe and Latin America in the 1820s., Tuscaloosa, University of Alabama Press, 2012.

49. López-Alves, Fernando, La formación del estado y la democracia en América Latina 1830-1910, Barcelona, Norma, 2003. 
definitivamente la derrota de los años veinte, aunque el carlismo, como ha explicado Canal, consiguió superar la crisis del legitimismo europeo de los años setenta del siglo XIX ${ }^{50}$. En todo caso, no lograría conquistar la cumbre de las instituciones solo controladas por el absolutismo en el Reino de las Dos Sicilias. En Nápoles, en 1849, la Cuarta restauración fue el momento de mayor éxito del legitimismo napolitano respecto a la contrarrevolución europea, pero justamente esto lo confinó en sus límites tradicionales, incapaz de absorber diversas concepciones de estado (la constitución) o de territorio (Sicilia). El resultado fue que, cuando el conflicto civil se entrecruzó con la gran guerra del Risorgimento (1859-61), justamente el éxito de la contrarrevolución y de sus victoriosas restauraciones multiplicó su aislamiento internacional y el peso de la fractura interna, contribuyendo de forma decisiva a la implosión del estado y a su desaparición. Al contrario, en los otros estados herederos del mundo borbónico, este conflicto se transformó (en España) o estaba definitivamente superado (en América Latina), y no devino nunca una cuestión de contraposición entre diversas identidades estatales. Solo en Nápoles el no resuelto conflicto entre revolución y contrarrevolución acabó por identificarse con las adscripciones nacionales, contraponiendo una patria (napolitana) a otra patria (italiana), dejando una herencia explosiva al jovencísimo heredero de Fernando II.

\section{La restauración fallida}

La muerte del rey evidenció las contradicciones de la última restauración borbónica. Los meridionales filoitalianos, reforzados por el consenso internacional y por la agresiva política de Cavour, participaron en masa en la revolución de 1860. El nuevo rey y sus hombres más próximos pensaron invertir la política de Fernando II, modificando los caracteres del bloque dominante, consolidado prácticamente desde 1799 , y aceptando liquidar el aparato puesto en pie por el padre durante la última restauración (1849), a cambio de la alianza con un sector liberal moderado ${ }^{51}$. La concesión de la constitución provocó, sin embargo, la implosión del reino. El patriotismo napolitano empezó a fragmentarse, el italiano se unifico definitivamente. Entre junio y septiembre de 1860, las tropas borbónicas se desbandaron, los liberales meridionales toma-

50. Canal, Jordi, El carlismo. Dos siglos de contrarrevolución en España, Madrid, Alianza Editorial, 2000; idem, Banderas blancas, boinas rojas. Una historia política del carlismo, 18761939, Madrid, Marcial Pons, 2006; Rújula, Pedro, Contrarrevolución. Realismo y Carlismo en Aragón y el Maestrazgo, 1820-1840, Zaragoza, Prensas de la Universidad, 2011.

51. MACRY, Paolo, Unità a Mezzogiorno. Come l'Italia ha messo insieme i pezzi, Bologna, Il Mulino, 2012. 
ron el control de las provincias y Garibaldi, que había liderado la enésima revuelta siciliana, entró triunfalmente en la capital ${ }^{52}$.

No hubo una transición pacífica. En septiembre, justo en el momento de mayor éxito de la revolución, empezó una poderosa contrarrevolución que duró años. El conflicto entre fidelidad dinástica y constitucionalismo liberal que había marcado durante medio siglo la política meridional y caracterizado las últimas dos restauraciones, quedó en segundo plano. Fue la guerra entre los dos nacionalismos, italiano y napolitano, la que obligó a la sociedad meridional a posicionarse definitivamente, adoptando un modelo nacional o defendiendo otro (Sicilia había elegido casi en bloque la Unificación). El ejército borbónico mostró voluntad de combatir. Solo la invasión piamontesa lo derrotó definitivamente. Luego, después de Gaeta, los partidarios de la dinastía intentaron una nueva restauración, en nombre del rey y de la independencia de las Dos Sicilias. La movilización rural (il Brigantaggio) duró varios años. También la alta jerarquía eclesiástica rechazó radicalmente la revolución unitaria. Solo un obispo (de 89) se adhirió al nuevo régimen, pero la Iglesia, aun no reconociendo el nuevo estado, evitó un dramático ajuste de cuentas. El significado general de la crisis se hace más claro en el interior del sistema internacional: si las primeras restauraciones fueron consolidadas por el cuadro de alianzas europeas, la última fracasó por su aislamiento casi completo.

A pesar de su fracaso, en los años siguientes la celebración de la defensa de la independencia de las Dos Sicilias devino el momento constitutivo de la identidad borbónica napolitana ${ }^{53}$. El mito de la restauración fallida estaba directamente vinculado a la reelaboración de un conflicto civil ininterrumpido que había marcado los decenios precedentes. En la memoria legitimista el enemigo interno era el responsable de la disolución de una compacta comunidad nacional. El político legitimista Scamaccia Luvarà escribió que durante más de sesenta años, desde 1794, los traidores se habían apartado en "secretos concilios... apoyando descarados los perjuicios de la patria..." ${ }^{44}$. La narración legitimista buscó en los sucesos de las restauraciones las razones de la propia reivindicación nacional, pero fue sobre todo la última defensa del reino el corazón de la epopeya borbónica, un mito en el cual no faltaban los elementos simbólicos, con su intensa capacidad de sugestión mitográfica: la

52. PinTo, Carmine, "La rivoluzione disciplinata del 1860. Cambio di regime ed élite politiche nel Mezzogiorno italiano", Contemporanea, $n^{\circ} 1$ (2013), pp. 39-68.

53. Casalena, Maria Pia (coord.), Antirisorgimento. Appropriazioni, critiche, delegittimazioni, Bologna, Pendragon, 2013.

54. Insogna, Angelo, Francesco secondo Re di Napoli, Storia del Reame delle Due Sicilie, Napoli, Gambella, 1898, pp. LV-LVII. 
bandera y la comunidad, el himno nacional y el rey, la independencia y la defensa frente al agresor extranjero, el héroe y el traidor.

Veteranos y militantes escribieron decenas de volúmenes de memorias, panfletos y ensayos. Todos, como el capitán Tommaso Cava, procedente de una familia de antiguas tradiciones militares, reivindicaron que "el ejército napolitano defendió la independencia Nacional" ${ }^{55}$. En la memoria de la generación de los combatientes de las Dos Sicilias la comunión entre el rey y los defensores de la patria se extendió a un concepto de nación más amplio. El mayor de artillería Pietro Quandel, hijo de un personaje importante de las jerarquías militares borbónicas, escribió en su relación del asedio de Gaeta que:

"La guarnición ha estado siempre sostenida por el pensamiento de cumplir con un deber sacro y mantener la fidelidad jurada, y ha sido incitada a cumplir con el ejemplo que les llevaron Sus Majestades el Rey Francisco II y la Reina María Sofía, y Sus Altezas Reales el Conde de Trani y el Conde de Caserta, que han compartido constantemente con los defensores de la Plaza peligros, privaciones, incomodidades" 56 .

Se desarrolló una épica colectiva que inmortalizó la voluntad de resistencia de los napolitanos a través de una serie de imágenes y temas eficaces para delinear identidad y autoconciencia: el desprecio por la prepotencia del extranjero, la traición, la llamada del rey, los héroes y los soldados populares. Lealtad y resistencia eran los puntos de partida insustituibles de esta narración que completó un recorrido que sirvió para unir definitivamente la nueva reivindicación nacional con el antiguo patriotismo representado por la unión con la casa real. Estas líneas confluyeron con la crítica legitimista de la Unificación, renovando la identidad patriótica borbónica justo cuando Italia devino una realidad y empezaban a transformarse los nacionalismos europeos ${ }^{57}$. La fuerza de esta reelaboración no superó nunca el círculo de los supervivientes y de la memoria partidaria, si bien estuvo acompañada de una nutrida propaganda legitimista europea, sobre todo, francesa ${ }^{58}$. La formación discursiva del nuevo patriotismo borbónico perdió rápidamente, por lo tanto, su eficacia. En la Europa de finales del XIX eran los estados quienes diseñaban las tradiciones polí-

55. Cava, Tommaso, Difesa nazionale napoletana di Tommaso Cava, capitano dello Stato Maggiore dell'Esercito delle Due Sicilie, Capo dello Stato Maggiore della Piazza di Capua durante l'assedio del 1860, Napoli, s.n., 1863.

56. Quandel, Pietro, Giornale della difesa di Gaeta da novembre 1860 a febbraio 1861, Roma, Angelo Placidi, 1863, p. 329.

57. Chabod, Federico, Lidea di nazione, Bari, Laterza, 1962; Hobsbawm, Eric J. y Ranger, Terence (coords.), Linvenzione della tradizione, Torino, Einaudi, 1987; Viroli, Maurizio, Per amore della Patria. Patriottismo e nazionalismo nella storia, Roma-Bari, Laterza, 1995.

58. Croce, Benedetto, Uomini e cose della vecchia Italia, Bari, Laterza, 1927. 
ticas nacionales. También en el Mezzogiorno los nacionalistas italianos construyeron un edificio basado en las ceremonias de conmemoración, en la glorificación de los patriotas y de los héroes de la independencia a través de los símbolos oficiales que construyeron la nueva religión de la patria. Los veteranos y los nostálgicos borbónicos eran excluidos del nuevo fenómeno de la instrucción primaria nacional, de las ceremonias públicas o de la masiva inauguración de monumentos. A pesar de todo esto, un sector minoritario del Mezzogiorno dio vida a una combativa batalla política, a menudo estrechamente vinculada al movimiento católico conservador, representada por viejos aristócratas (a partir de las familias que regresaron a Nápoles después de 1870), ex militares, sacerdotes, gentes del medio rural, arropados por periódicos como La discussione, el Contemporaneo, La libertà cattolica, L'Italia Reale, el Vero guelfo, la Lotta, la Indipendenza, el Guelfo dell'indipendenza del Mezzogiorno y asociaciones (la Asociación borbónica estuvo activa en Nápoles hasta 1914). El mito de la restauración fallida arraigó en el fondo de una tradición y de una cultura y floreció en las crisis más agudas y en los momentos de reivindicación del Mezzogiorno: las publicaciones periódicas napolitanas de finales del XIX, la cultura populista de la segunda Posguerra, o la social radical de los años setenta. En el 150 aniversario, con mayor impacto, tuvieron lugar decenas de eventos: la conmemoración del general carlista Borges en presencia de todos los herederos de la familia real borbónica, la de los caídos en la fortaleza de Gaeta, los monumentos o las tarjetas postales de guerrilleros legitimistas como el sargento Romano en Apulia. Todos ellos son elementos que explican cómo aún hoy puede apreciarse el peso del intento de nacionalización del régimen borbónico que, unido a las críticas al estado unitario, ha contribuido a reforzar el paradigma excepcional de la historia meridional.

En todo caso, este sentimiento, en tanto que difuso, no tuvo nunca la fuerza para poner en tela de juicio los resultados de la revolución de 1860. Hasta aquel momento el Mezzogiorno había experimentado la república, la monarquía absoluta, el centralismo administrativo napoleónico, el absolutismo borbónico y la monarquía constitucional regional. Había conocido guerras civiles e internacionales, cuatro invasiones extranjeras, modelos políticos y visiones ideológicas opuestas. Las cuatro restauraciones, entre 1799 y 1849 , habían evidenciado la capacidad de la monarquía borbónica y de los antiguos estados italianos de renovarse, mostrando una potencial carga modernizadora abierta a una ulterior evolución posible y capaz de enfrentarse con estas dinámicas. Las propias restauraciones borbónicas, sin embargo, no habían conseguido asimilar las fracturas históricas del Mezzogiorno. La cuestión siciliana, las desavenencias sociales y sobre todo las político-ideológicas, el enfrenta- 
miento con el liberalismo, la formación de opuestas identidades nacionales en el mismo estado, habían convertido en perenne el conflicto civil ${ }^{59}$. El fracaso de las restauraciones estuvo en su fallida asimilación y luego en la incompleta resolución del problema nacional napolitano e italiano. El éxito de la contrarrevolución fue también su condena, porque fragmentó una unidad política hasta entonces coherente. Un caso único respecto a todos los estados y los territorios herederos de la monarquía católica, donde la derrota de la contrarrevolución había modificado el proceso de integración de las comunidades nacionales. Al contrario, en Nápoles, la radicalización del enfrentamiento entre estado monárquico borbónico y oposición política liberal modeló un concepto de nacionalismo alternativo y no logró encontrar una síntesis. Las últimas restauraciones llevaron a cabo una fórmula nacional que permaneció siempre incompleta y dividida, a diferencia del Piamonte saboyano, que en el nacionalismo italiano encontró la síntesis entre sus dos componentes internos también radicales (olvidando para siempre el rigor legitimista de los Saboya en 1815 y en $1821^{60}$ ). La guerra de 1860-66 representó la última respuesta a la presencia de diferentes formas de ver y representar el estado, y los cambios de la política y de la sociedad. Caído el reino y fallida la última tentativa de restauración, el resultado fue que sus élites estuvieron obligadas a desempeñar un rol secundario en el nuevo orden italiano, mientras que el Mezzogiorno devino progresivamente una de las cuestiones más problemáticas para la nueva nación.

59. PinTo, Carmine, "Tempo di guerra. Conflitti, patriottismi e comunità politiche opposte nel Mezzogiorno d'Italia (1859-1866)", Meridiana, no 76 (2013), pp. 57-84.

60. PASSERIN D'EnTREves, Ettore, L'Ultima battaglia politica di Cavour, i problemi dell' unificazione italiana, Torino, Ilte, 1956; Viarengo, Adriano, Cavour, Roma, Salerno, 2010; RoMEO, Rosario, Cavour e il suo tempo (1842-1861), Roma-Bari, Laterza, 2012. 